\title{
Gel Electrophoresis of Proteins
}

\author{
Laura García-Descalzoํ, Eva García-López¹, \\ Alberto Alcázar ${ }^{2}$, Fernando Baquero ${ }^{1,3}$ and Cristina Cid $^{1 *}$ \\ ${ }^{1}$ Microbial Evolution Laboratory, Center for Astrobiology (CSIC-INTA), \\ ${ }^{2}$ Department of Investigation, Hospital Ramon y Cajal, \\ ${ }^{3}$ Department of Microbiology, Hospital Ramon y Cajal, Madrid, \\ Spain
}

\section{Introduction}

Gel electrophoresis is a widely known group of techniques used to separate and identify macromolecules as DNA, RNA, or proteins based on size, form, or isoelectric point. The separation of molecules by electrophoresis is based on the fact that charged molecules migrate through a gel matrix upon application of an electric field. These techniques have become a main tool in biochemistry, molecular biology, analytical chemistry and proteomics. Gel electrophoresis is usually used for analytical purposes, but may be a preparative technique to partially purify molecules before applying other techniques, mainly mass spectroscopy to perform proteome analysis (Wasinger et al., 1995).

Although gel electrophoresis is a classical method, in the last decade there has been resurgence in the use of protein electrophoresis with the aim to interpret the great set of data generated by the "omic" techniques. Among them, proteomics may be defined as the comprehensive analysis of the entire protein complement expressed in any biological sample at a given time under specific conditions. The full characterization of the proteome is a formidable challenge as proteins may be subjected to post-translational modifications, have large degrees of dynamic range and be only transiently expressed. In this chapter we will review the general trends concerning the gel electrophoresis of proteins, as well as summarize background information and practical protocols for its application in analytical chemistry and in proteomics.

\section{Polyacrylamide gel electrophoresis (SDS-PAGE)}

Gel electrophoresis of proteins with a polyacrylamide matrix, commonly called polyacrylamide gel electrophoresis (PAGE) is undoubtedly one of the most widely used techniques to characterize complex protein mixtures. It is a convenient, fast and inexpensive method because they require only the order of micrograms quantities of protein.

The proteins have a net electrical charge if they are in a medium having a $\mathrm{pH}$ different from their isoelectric point and therefore have the ability to move when subjected to an electric

${ }^{*}$ Corresponding Author 
field. The migration velocity is proportional to the ratio between the charges of the protein and its mass. The higher charge per unit of mass the faster the migration.

Proteins do not have a predictable structure as nucleic acids, and thus their rates of migration are not similar to each other. They can even not migrate when applying an electromotive force (when they are in their isoelectric point). In these cases, the proteins are denatured by adding a detergent such as sodium dodecyl sulfate (SDS) to separate them exclusively according to molecular weight. This technique was firstly introduced by Shapiro et al. (1967). SDS is a reducing agent that breaks disulfide bonds, separating the protein into its sub-units and also gives a net negative charge which allows them to migrate through the gel in direct relation to their size. In addition, denaturation makes them lose their tertiary structure and therefore migration velocity is proportional to the size and not to tertiary structure.

Some highlights of the polyacrylamide gel electrophoresis are:

- Gels suppress the thermal convection caused by application of the electric field, and can also act as a sieving medium, retarding the passage of molecules; gels can also simply serve to maintain the finished separation, so that a post electrophoresis stain can be applied.

- The polyacrylamide gels are formed by polymerization of acrylamide by the action of a cross-linking agent, the bis-acrylamide, in the presence of an initiator and a catalyst. Persulfate ion $\left(\mathrm{S}_{2} \mathrm{O}_{8}-\right)$, that is added as ammonium persulfate (APS) is the gel solidifying initiator and a source of free radicals, while TEMED $(\mathrm{N}, \mathrm{N}, \mathrm{N}$ ', N'tetramethylethylenediamine) catalyzes the polymerization reaction by stabilizing these free radicals. In some situations, for example, isoelectric focusing the presence of persulfate can interfere with electrophoresis, so ribofavin and TEMED are used instead.

- Acrylamide solutions are degassed as oxygen is an inhibitor of polymerization. Moreover, the polymerization releases heat that could cause the formation of bubbles within the gel.

- The rate of polymerization is determined by the concentration of persulfate (catalyst) and TEMED (initiator).

- The ratio between of acrylamide/bisacrylamide as well as the total concentration of both components, affects the pore size and rigidity of the final gel matrix. These, in turn, affect the range of protein sizes that can be resolved. The size of the pores created in the gel is inversely related to the amount of acrylamide used. For instance, a $7 \%$ polyacrylamide gel has larger pores than a $12 \%$ polyacrylamide gel. Gels with a low percentage of acrylamide are typically used to resolve large proteins, and high percentage gels are used to resolve small proteins. "Gradient gels" are specially prepared to have low percent-acrylamide at the top and high percent-acrylamide at the bottom, enabling a broader range of protein sizes to be separated.

The acrylamide gel electrophoresis systems may be performed using one or more buffers, in these cases we speak of continuous phosphate buffer system (Weber and Osborn, 1968) or discontinuous buffer systems (Ornstein, 1964; Davis, 1964). Laemmli (1970) adopted the discontinuous electrophoresis method and the term "Laemmli buffer" is often used to describe the tris-glycine buffer system that is utilized during SDS-PAGE. 
In discontinuous systems the first buffer ensures the migration of all proteins in the front of migration, what causes the accumulation of the entire sample that has been loaded into the well. The separation really begins from the moment when the migration front reaches the boundary of the second buffer. The first gel, "stacking", has larger pore (lower percentage of acrylamide/bisacrylamide) and has a $\mathrm{pH}$ more acidic than the second gel which is what really separates proteins. This system is particularly suitable for analyzing samples diluted without losing resolution (Westermeier, 2005).

The resolution of peptides below $14 \mathrm{kDa}$ is not sufficient in conventional tris-glycine systems. This problem was solved by the development of a new system by Schägger and von Jagow (1978). In this method an additional spacer gel is introduced, the molarity of the buffer is increased and tricine is used as terminated ion instead of glycine. This method yields linear resolution from 100 to $1 \mathrm{kDa}$.

\section{Detection of proteins in gels}

Proteins separated on a polyacrylamide gel can be detected by various methods, for instance dyes and silver staining.

- Dyes

The Coomassie blue staining allows detecting up to 0.2 to $0.6 \mu \mathrm{g}$ of protein, and is quantitative (linear) up to 15 to $20 \mu \mathrm{g}$. It is often used in methanol-acetic acid solutions and is discolored in isopropanol-acetic acid solutions (Fig. $1 \mathrm{~A}$ ). For staining of 2-DE gels it is recommended to remove ampholytes by adding trichloroacetic (TCA) to the dye and subsequently discolor with acetic acid.

\section{- $\quad$ Silver staining}

It is an alternative to routine staining protein gels (as well as nucleic acids and lipopolysaccharides) because its ease use and high sensitivity (50 to 100 times more sensitive than Coomassie blue staining) (Fig. 1 B). This staining technique is particularly suitable for two-dimensional gels.
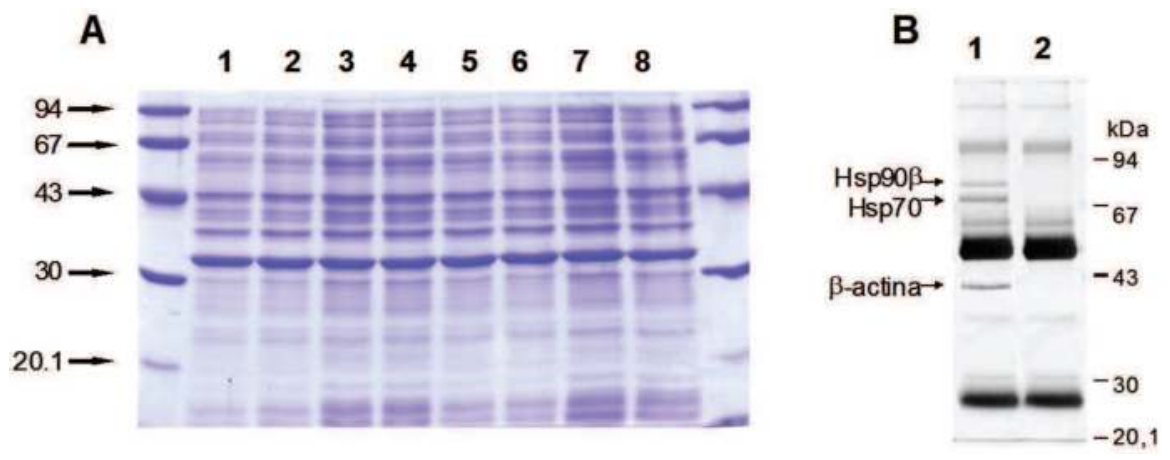

Fig. 1. SDS-PAGE.

Proteins separated on SDS-PAGE and detected by Coomassie blue (A) and silver staining (B). Standards of proteins to know molecular weight are also loaded at edges. (Cid et al., 2004). 
- Detection of radioactive proteins by autoradiography

The autoradiography is a detection technique of radioactively labeled molecules that uses photographic emulsions sensitive to radioactive particles or light produced by an intermediate molecule. The emulsion containing silver is sensitive to particulate radiation (alpha, beta) or electromagnetic radiation (gamma, light...), so that it precipitates as metallic silver. The emulsion will develop as dark precipitates in the region in which radioactive proteins are detected.

\section{Native PAGE}

Depending on the state of the protein (native or denatured) along the electrophoretic process, the techniques are classified into native and denaturing electrophoresis.

- Denaturing electrophoresis, the most common, is when the protein undergoes migration ensuring complete denaturation (loss of three-dimensional structure). In this case, migration is proportional to the load and the size of the molecule but not to its form. The most commonly used denaturing agent is the detergent SDS.

- Native electrophoresis is when the protein undergoes migration without denaturation. In this situation, proteins migrate according to their charge, size and shape. Furthermore, in some cases the interactions between subunits and between proteins are kept, separating at the level of complexes. Buffer systems used in this electrophoresis are: tris-glycine ( $\mathrm{pH}$ range 8.3 to 9.5$)$, tris-borate ( $\mathrm{pH}$ range 7.0 to 8.5 ) and tris-acetate ( $\mathrm{pH}$ range 7.2 to 8.5 ).

- Blue native electrophoresis permits a high resolution separation of multiprotein complexes under native conditions. This technique consists of polyacrylamide gel electrophoresis where the nondenaturing compound Coomassie blue G-250 is added to both the sample and to the electrophoresis buffers to confer a negative charge on the protein complexes so they can migrate intact toward the anode. Using this methodology, many samples can be concurrently separated during a single electrophoretic run, and a direct comparison of protein complexes readily allows for the identification of differences in protein expression and direct further functional analysis.

\section{Immunodetection of proteins by western blot}

Western blot is a widely used method in molecular biology and biochemistry to detect proteins in a sample of cell homogenate or extract. The proteins are transferred from the gel to a membrane -made of nitrocellulose, nylon or polyvinylidene difluoride (PVDF)-, where they are examined using specific antibodies to the protein. As a result, the amount of protein in a sample can be examined and it is also possible to compare levels among various analytical groups.

The method was initiated in the laboratory of George Stark at Stanford. The name "western blot" was given to the technique by Burnette (1981), comparing it with the "southern blot" technique for DNA detection developed by Edwin Southern. The detection of RNA is also called Northern blotting.

The most powerful method is the transference of proteins from the gel to a membrane by applying an electric field perpendicular to the gel. There are however other methods of 
transferring or applying a protein on the membrane. The simplest is to apply it directly as a small drop of a concentrated solution on the membrane. The absorption of the drop causes the adhesion of the protein to the membrane, leaving it as a spot or "dot" (this is the case of the "dot blot"). There are devices that make possible the application of proteins to the membrane directly, using a suction that facilitates the penetration of the solution, and are named "dot blot" or "slot blot" on the basis that the proteins were applied as a circular drop or a line.

Working with proteins bound to a membrane has advantages over employment within the gel:

- Staining and discolor are faster.

- No staining occurs to ampholytes in isoelectric focusing gels.

- Smaller amounts of proteins are detected as they are concentrated at the surface and not diluted across the thickness of the gel.

- The membranes are much easier to manipulate than the gel itself.

\section{Blotting procedure}

It consists of 5 stages:

1. Immobilization of proteins on the membrane either by transference (electrophoresis, suction, pressure...) or by direct application. The procedure starts piling a flat sponge on filter paper soaked in transference buffer, the gel, the membrane in direct contact with the gel plus filter paper and finally a flat sponge (Fig. 2 A). This set is included between two layers of perforated plastic and placed in a tank which is a saline solution (transference buffer) and two plate electrodes (designed to achieve a uniform field across the surface of the gel). They are disposed so that the gel is toward the anode (-) and the membrane to the cathode $(+)$.

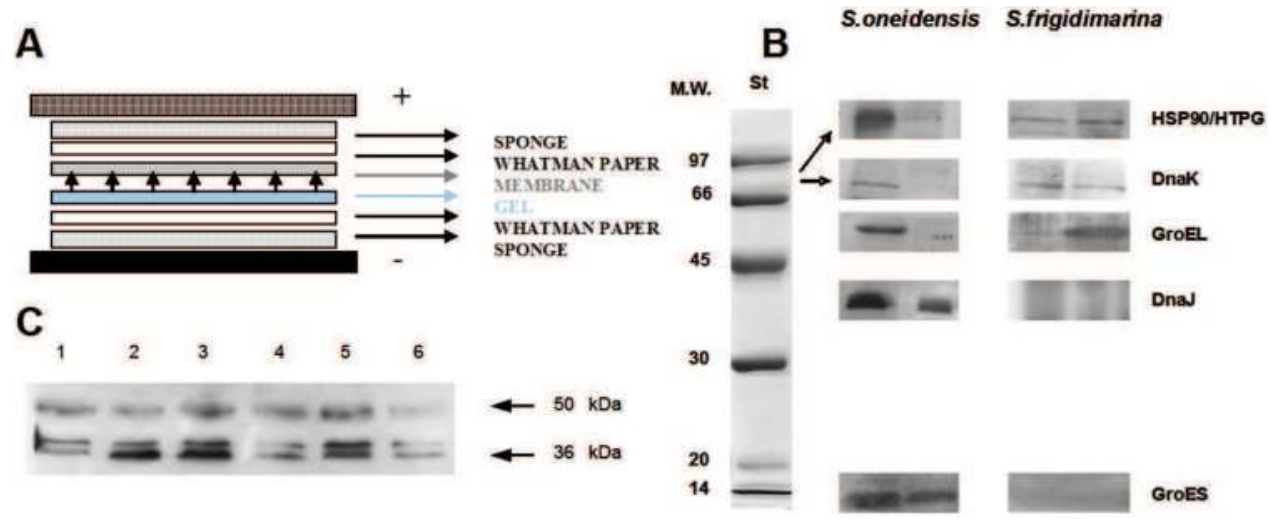

Fig. 2. Western blot.

Scheme of the components used for immobilization of proteins on a membrane by western blot (A). Examples of western blot performed in extracts from bacterial cells (B) and rat neurons $(\mathrm{C})$ with specific antibodies. 
2. Saturation of all binding sites of proteins in the membrane not occupied to prevent nonspecific binding of antibodies, which are proteins.

3. Incubation with primary antibody against the protein of interest.

4. Incubation with secondary antibodies, or reactives acting as ligands of the primary antibody bound to enzymes or other markers. The proteins labeled with enzymes are visible by incubation with appropriate substrates to form insoluble colored products in the place where the protein were. There are several possibilities:

Enzyme coupled secondary antibodies: an antibody to the specific binding antibody is conjugated to the enzyme peroxidase or alkaline phosphatase (Blake et al., 1984).

Another possibility is the use of an amplifying enzyme which is part of a biotin-avidinperoxidase complex (Hsu et al., 1981) or a complex with alkaline phospohatase.

Enhanced chemiluminescence (ECL) is other commonly used method for protein detection in western blots (Laing, 1986). ECL is based on the emission of light during the horse radish peroxides (HRP)- and hydrogen peroxide-catalyzed oxidation of luminol. The emitted light is captured on film or by a CCD camera, for qualitative or semiquantitative analysis. This method allows stripping and re-probing the blot with different antibodies. Two examples of western blot with different antibodies can be seen in Fig. 2 B and $\mathrm{C}$.

\section{Isoelectric focusing (IEF)}

This technique is based on the movement of molecules in a $\mathrm{pH}$ gradient. Amphoteric molecules such as amino acids and proteins are separated in an environment where there is a difference of potential and $\mathrm{pH}$ gradient. The region of the anode $(+)$ is acidic and the cathode (-) is alkaline. Between them down a $\mathrm{pH}$ gradient such that the molecules to be separated have their isoelectric point within the range. Substances that are initially in regions with a $\mathrm{pH}$ below its isoelectric point are positively charged and migrate towards the cathode, while those that are in media with $\mathrm{pH}$ lower than its $\mathrm{pI}$ will have negative charge and migrate towards the anode. The migration will lead to a region where the $\mathrm{pH}$ coincide with its $\mathrm{pI}$, have a zero net charge (form zwitterions) and stop. Thus amphoteric molecules are located in narrow bands where the $\mathrm{pI}$ coincides with the $\mathrm{pH}$. In this technique the point of application is not critical as molecules will always move to their $\mathrm{pI}$ region. The stable $\mathrm{pH}$ gradient between the electrodes is achieved using a mixture of low molecular weight ampholytes which pI covers a preset range of $\mathrm{pH}$.

\section{Two-dimensional gel electrophoresis}

Two-dimensional gel electrophoresis (2-DE) is based on separating a mixture of proteins according to two molecular properties, one in each dimension. The most used is based on a first dimension separation by isoelectric focusing and second dimension according to molecular weight by SDS-PAGE (O'Farrel, 1975).

The general workflow in a 2-DE experiment would be: 

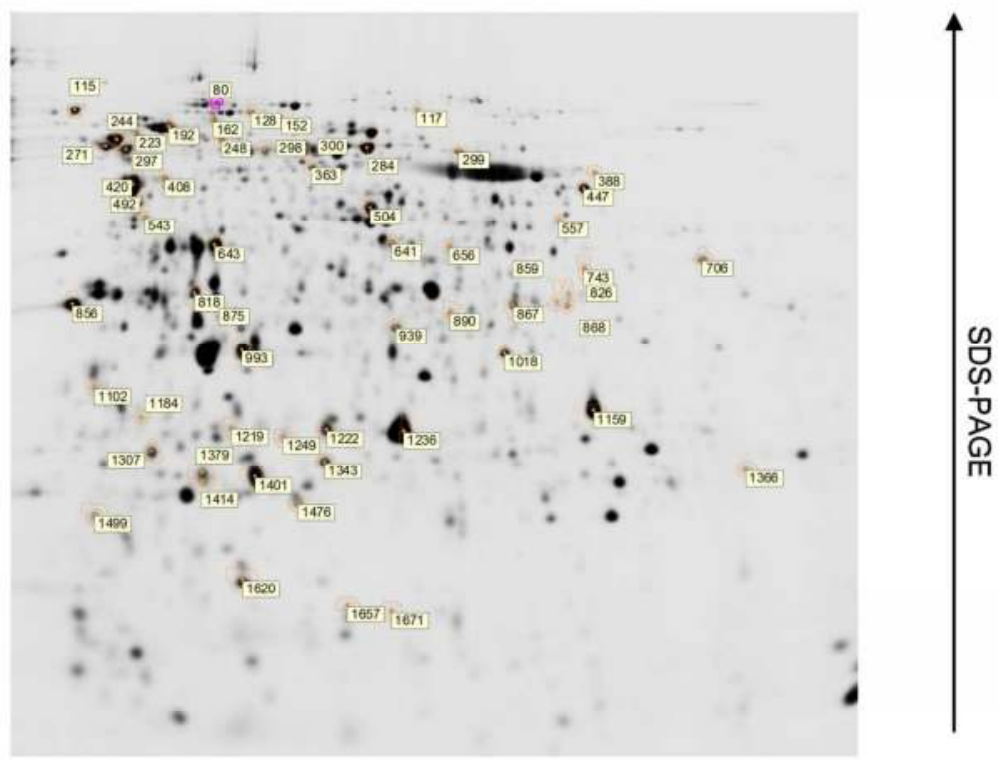

\section{$\mathrm{pH} 3$}

Fig. 3. 2-DE preparative gels.

Proteins of Chlamydomonas reinhardtii resolved by 2-DE from preparative gels stained with MALDI-MS compatible silver reagent for peptide mass fingerprinting analysis. First dimension: isoelectric focusing in a 3-11 $\mathrm{pH}$ gradient. Second dimension: SDS-PAGE in a $12 \%$ acrylamide ( $2.6 \%$ crosslinking) gel (1.0 mm thick). Numbered spots marked with circle correspond to proteins compared to be subsequently identified by MALDI-TOF MS. (Cid et al., 2010).

\section{- Sample Preparation}

The method of sample preparation depends on the aim of the research and is crucial to the success of the experiment. Factors such as the solubility, size, charge, and isoelectric point (pI) of the proteins of interest enter into sample preparation. Sample preparation is also important in reducing the complexity of a protein mixture. The protein fraction to be loaded on a 2-DE gel must be in a low ionic strength denaturing buffer that maintains the native charges of proteins and keeps them soluble.

- First-Dimension Separation

This part is performed by IEF. Using this technique, proteins are separated on the basis of their $\mathrm{pI}$, the $\mathrm{pH}$ at which a protein carries no net charge and will not migrate in an electrical field. 
- Equilibration

A conditioning step is applied to proteins separated by IEF prior to the second-dimension run. This process reduces disulfide bonds and alkylates the resultant sulfhydryl groups of the cysteine residues. Concurrently, proteins are coated with SDS for separation on the basis of molecular weight.

- Second-Dimension Separation

This part is performed by SDS-PAGE. The choice for the gel depends on the protein molecular weight range to be separated. The ability to run many gels at the same time and under the same conditions is important for the purpose of gel-to-gel comparison.

- $\quad$ Staining

In order to visualize proteins in gels, they must be stained in some manner. The selection of staining method is determined by several factors, including desired sensitivity, linear range, ease of use, expense, and the type of imaging equipment available. At present there is no ideal universal stain. Sometimes proteins are detected after transference to a membrane support by western blotting.

- Image Analysis

The ability to collect data in digital form is one of the major factors that enable 2-DE gels to be a practical means of collecting proteome information. It allows unprejudiced comparison of gels and cataloging of immense amounts of data. Many types of imaging devices interface with software designed specifically to collect, interpret, and compare proteomics data. One of the biggest problems in 2-DE is the analysis and comparison of complex mixtures of proteins. Currently there are databases capable of comparing two-dimensional gel patterns. These systems allow automatic comparison of spots for the precise identification of those needed in the quantitative analysis.

- Protein Identification

Once interesting proteins are selected by differential analysis or other criteria, the proteins can be excised from gels, distained and digested to prepare their identification by mass spectrometry (Fig. 5 A). This technique is known as peptide mass fingerprinting. The ability to precisely determine molecular weight by matrix-assisted laser desorption/ionizationtime of flight mass spectrometry (MALDI-TOF MS) and to search databases for peptide mass matches has made high-throughput protein identification possible. Proteins not identified by MALDI- TOF can be identified by sequence tagging or de novo sequencing using the Q-TOF electrospray LC-MS-MS (Fig. 5 B).

\section{Two-dimensional fluorescence difference gel electrophoresis (2-D DIGE)}

2-D Fluorescence Difference Gel Electrophoresis (2-D DIGE) is a method that labels protein samples prior to 2-DE, enabling accurate analysis of differences in protein abundance between samples (Mackintosh et al., 2003). It is possible to separate up to three different samples within the same 2-DE gel. The technology is based on the specific properties of fluorescent cyanine dyes that are spectrally resolvable and size- and charge-matched (Ünlü 
et al., 1997). Identical proteins labeled with each of the three dyes (Cy2, Cy3 and Cy5) will migrate to the same position on a 2-DE gel (Fig. 4). This ability to separate more than one sample on a single gel permits the inclusion of up to two samples and an internal standard (internal reference) in every gel. The internal standard is prepared by mixing together equal amounts of each sample in the experiment and including this mixture on each gel (GarcíaDescalzo et al. 2011).

There are several analysis software programs developed to exploit the advantages of fluorescent dyes. They enable the detection, quantization, matching, and analysis of gels. The algorithm in this type of software co-detects overlaid image pairs and produces identical spot boundaries for each pair. This enables direct spot volume ratio measurements and therefore produces an accurate comparison of every protein with its representative ingel internal standard. The software automatically performs detection, background subtraction, quantization, and normalization, which takes into account any differences in the dyes, i.e. molar extinction coefficient, quantum yields, etc.

A

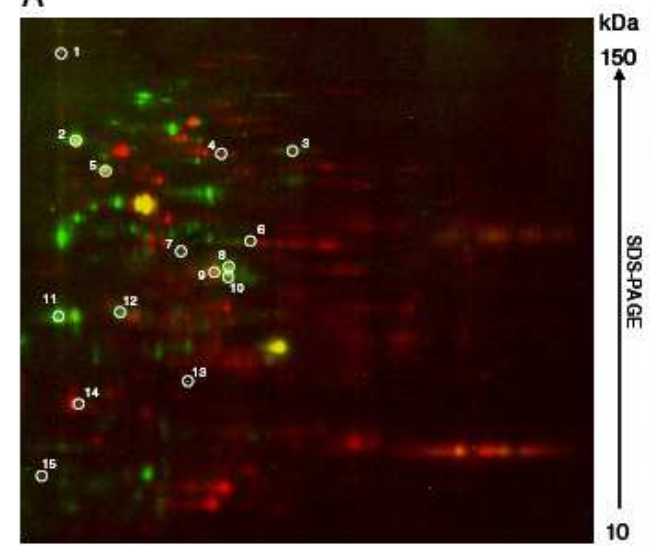

$\mathrm{pH} 3$

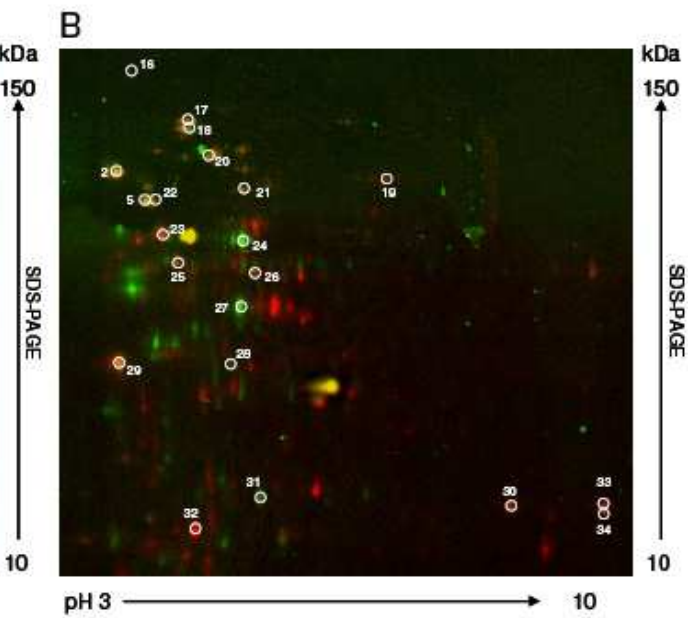

Fig. 4. Example of 2D-DIGE gels.

Cell extracts were obtained from S. oneidensis cultured at $30^{\circ} \mathrm{C}(\mathrm{A})$ and $4{ }^{\circ} \mathrm{C}(\mathrm{B})$, and subjected to immunoprecipitation with monoclonal antibody. Immunoprecipitates were resolved by 2D-DIGE gels following image analysis. Numbered spots marked with circles corresponded to proteins identified by MALDI-TOF MS. (Garcia-Descalzo et al., 2011).

\section{Protein identification by matrix-assisted laser desorption/ionization-time of flight (MALDI-TOF) mass spectrometry}

Mass spectrometry is a technique to analyze with high accuracy the composition of different chemical elements and atomic isotopes splitting their atomic nuclei according to their masscharge ratio $(\mathrm{m} / \mathrm{z})$. It can be used to identify different chemical elements that form a compound or to determine the isotopic content of different elements in the same compound. 
Firstly, the material to be analyzed is ionized and ions are then transported by magnetic or electric fields to the mass analyzer. Techniques for ionization have been key to determine what types of samples can be analyzed by mass spectrometry. Two techniques are often used with liquid and solid biological samples: electro spray ionization and laser matrixassisted laser desorption/ionization (MALDI). In the MALDI ionization analytes cocrystallized with a suitable matrix are converted into ions by the action of a laser. This source of ionization is usually associated with a time of flight analyzer (TOF) in which the ions are separated according to their mass-charge after being accelerated in an electric field. At last, a mass spectrometer detector records the charge induced or current produced when an ion passes by or hits a surface. A mass spectrum is registered for each protein (Fig. $5 \mathrm{~A}$ ).

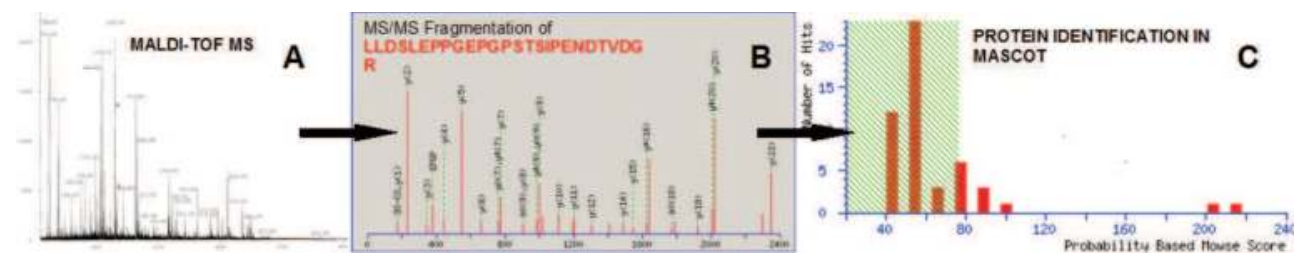

Fig. 5. Protein identification by MALDI-TOF MS.

Workflow of protein identification developing MALDI-TOF MS assay (A), followed by MS/MS fragmentation of peptides (B) and analysis of spectral data with the MASCOT database search algorithm (C).

\section{Software and database search algorithms to analyze spectral data}

A variety of tools and commercially available software exist that allow for protein identification from peptide sequences determined by mass spectrometry (or other sequencing techniques) (Fig $5 \mathrm{C}$ ).

Some examples of database search programs and algorithms are:

- SEQUEST - identifies collections of tandem mass spectra to peptide sequences that have been generated from databases of protein sequences. It was one of the first, if not the first, database search program. While very successful in terms of sensitivity, it is quite slow to process data and there are concerns against specificity, especially if multiple posttranslational modifications (PTMs) are present (Jimmy et al., 1994).

- Mascot - is a powerful search engine that uses mass spectrometry data to identify proteins from primary sequence databases (www.matrixscience.com) (Perkins et al., 1999).

- Scaffold 3 - is a software which produces a confidence level for protein identification from one or more Mascot, Sequest, X! Tandem, or Phenyx searches. It can be used in conjunction with a MS/MS search engine in order to validate/visualize data across multiple experimental runs as well as provide a more accurate protein probability (www.proteomesoftware.com).

\section{Conclusion}

Nowadays, many fully sequenced genomes are available however only a part of the sequence can be directly correlated with a biological function. It has been found that cells 
express several thousand different proteins and each may experience many changes in response to different microenvironments but there is a low correlation between mRNA abundance and protein levels (Haynes et al., 1998). Despite alternative technologies that have emerged, gel electrophoresis of proteins together with mass spectrometry has allowed the interpretation of a great set of data generated by the "omics". Understanding the proteome of an organism thanks to these techniques makes available a dynamic picture of all proteins expressed, at any given moment and under specified conditions of time and environment.

\section{Acknowledgement}

We are indebted to Drs. M. Martinez-Gomariz and C. Gil from Proteomic Unit of the Parque Científico de Madrid. This research was supported by grants CTM/2008-00304/ANT and CTM2010-12134-E/ANT from the Spanish Ministerio de Ciencia e Innovación.

\section{References}

Blake, M. S.; Johnston, K. H.; Russell-Jones, G. J. \& Gotschlich, E. G. (1984). A rapid, sensitive method for detection of alkaline phosphatase-conjugated anti-antibody on Western blots. Anal. Biochem 136:175-179.

Burnette, W. N. (1981). "Western Blotting": Electrophoretic transfer of proteins from sodium dodecyl sulfate-polyacrylamide gels to unmodified nitrocellulose and radiographic detection with antibody and radioiodinated protein A. Analytical Biochemistry. 112:195-203.

Cid, C.; Alvarez-Cermeño, J. C.; Camafeita, E.; Salinas, M \& Alcázar, A. (2004). Antibodies reactive to heat shock protein 90 induce oligodendrocyte precursor cell death in culture. Implications for demyelination in multiple sclerosis. FASEB J. 18:409-411.

Cid, C.; García-Descalzo, L.; Casado-Lafuente, V.; Amils, R. \& Aguilera, A. (2010). Proteomic analysis of the response of an acidophilic strain of Chlamydomonas sp. (Chlorophyta) to natural metal-rich water. Proteomics. 10:2026-36.

Davis, B. J. (1964). Disc electrophoresis. Method and application to human serum proteins. Ann N Y Acad Sci. 121:404-427.

García-Descalzo, L.; Alcázar, A.; Baquero, F. \& Cid, C. (2011). Identification of in vivo HSP90-interacting proteins reveals modularity of HSP90 complexes is dependent on the environment in psychrophilic bacteria. Cell Stress Chaperones. 16:203-218.

Haynes, P. A.; Gygi, S. P.; Figeys, D. \& Aebersold, R. (1998). Proteome analysis: biological assay or data archive? Electrophoresis. 19:1862-1871.

Hsu, D. M.; Raine, L. \& Fanger, H. (1981). Use of avidin-biotin-peroxidase complex in immunoperoxidase techniques. J Histochem Cytochem. 29:577-580.

Jimmy, K. E.; McCormack, A. L. \& Yates, J. R. (1994). An Approach to Correlate Tandem Mass Spectral Data of Peptides with Amino Acid Sequences in a Protein Database. J Am Soc Mass Spectrom. 5:976-989.

Laemmli, U. K. (1970). Cleavage of Structural Proteins during the Assembly of the Head of Bacteriophage T4. Nature. 227:680-685.

Laing, P. (1986). Luminescent visualization of antigens on blots. J Immunol Methods. 92:161165. 
Mackintosh, J. A.; Choi, H. Y.; Bae, S. H.; Veal, D. A.; Bell, P. J.; Ferrari, B. C.; Van Dyk, D. D.; Verrills, N. M.; Paik, Y. K. \& Karuso, P. (2003). A fluorescent natural product for ultra sensitive detection of proteins in one-dimensional and two-dimensional gel electrophoresis. Proteomics. 3:2273-2288.

O'Farrel, P. H. (1975). High resolution two-dimensional electrophoresis of proteins. J Biol Chem. 250:4007-4021.

Ornstein L. (1964). Disc electrophoresis. Background and theory. Ann NY Acad Sci. 121:32149.

Perkins, D. N.; Pappin, D. J. C.; Creasy, D. M. \& Cottrell, J. S. (1999). Probability-based protein identification by searching sequence databases using mass spectrometry data. Electrophoresis. 20:3551-3567.

Schägger, H. \& von Jagow, G. (1987). Tricine-sodium dodecyl sulfate-polyacrylamide gel electrophoresis for the separation of proteins in the range from 1 to $100 \mathrm{kDa}$. Anal Biochem. 166:368-79.

Shapiro, A. L.; Viñuela, E. \& Maizel, J. V. (1967). Molecular weight estimation of polypeptide chains by electrophoresis in SDS-polyacrylamide gels. Biochem Biophys Res Commun. 28:815-820.

Ünlü, M.; Morgan, M. E. \& Minden, J. S. (1997). Difference gel electrophoresis: a single gel method for detecting changes in protein extracts. Electrophoresis. 18:2071-2077.

Wasinger, V. C.; Cordwell, S. J.; Cerpa-Poljak, A.; Yan, J. X.; Gooley, A. A.; Wilkins, M. R.; Duncan, M. W.; Harris, R.; Williams, K. L. \& Humphery-Smith, I. (1995). Progress with gene-product mapping of the Mollicutes: Mycoplasma genitalium. Electrophoresis. 16:1090-4.

Weber, K. \& Osborn M. (1968). The reliability of molecular wight determinations by dodecyl sulfate-polyacrylamide gel electrophoresis. J Biol Chem. 244:4406-4412.

Westermeier, R. (2005). Electrophoresis in practice. Wiley-VCH Verlag GmbH \& Co. KGaA, Weinheim. 


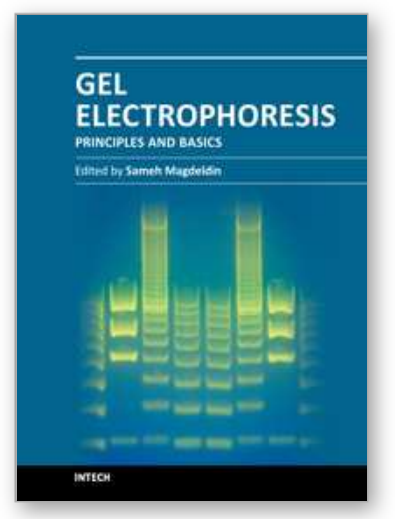

\author{
Gel Electrophoresis - Principles and Basics \\ Edited by Dr. Sameh Magdeldin
}

ISBN 978-953-51-0458-2

Hard cover, 346 pages

Publisher InTech

Published online 04, April, 2012

Published in print edition April, 2012

Most will agree that gel electrophoresis is one of the basic pillars of molecular biology. This coined terminology covers a myriad of gel-based separation approaches that rely mainly on fractionating biomolecules under electrophoretic current based mainly on the molecular weight. In this book, the authors try to present simplified fundamentals of gel-based separation together with exemplarily applications of this versatile technique. We try to keep the contents of the book crisp and comprehensive, and hope that it will receive overwhelming interest and deliver benefits and valuable information to the readers.

\title{
How to reference
}

In order to correctly reference this scholarly work, feel free to copy and paste the following:

Laura García-Descalzo, Eva García-López, Alberto Alcázar, Fernando Baquero and Cristina Cid (2012). Gel Electrophoresis of Proteins, Gel Electrophoresis - Principles and Basics, Dr. Sameh Magdeldin (Ed.), ISBN: 978-953-51-0458-2, InTech, Available from: http://www.intechopen.com/books/gel-electrophoresis-principlesand-basics/gel-electrophoresis-of-proteins

\section{INTECH}

open science | open minds

\section{InTech Europe}

University Campus STeP Ri

Slavka Krautzeka 83/A

51000 Rijeka, Croatia

Phone: +385 (51) 770447

Fax: +385 (51) 686166

www.intechopen.com

\section{InTech China}

Unit 405, Office Block, Hotel Equatorial Shanghai

No.65, Yan An Road (West), Shanghai, 200040, China

中国上海市延安西路 65 号上海国际贵都大饭店办公楼 405 单元

Phone: +86-21-62489820

Fax: +86-21-62489821 
(C) 2012 The Author(s). Licensee IntechOpen. This is an open access article distributed under the terms of the Creative Commons Attribution 3.0 License, which permits unrestricted use, distribution, and reproduction in any medium, provided the original work is properly cited. 